\title{
Explaining Gender Differentials In Scholarly Productivity: The Case Of Academic Economists
}

Susan Washburn Taylor, (Email: taylosw@millsaps.edu), Millsaps College Blakely Fox Fender, (Email: foxmb@millsaps.edu), Millsaps College

Kimberly Gladden Burke, (Email: burkekg@millsaps.edu), Millsaps College

\begin{abstract}
The purpose of this study is to examine the impact of personal characteristics, institutional factors, and time-competing workplace requirements on scholarly productivity in peer-reviewed economics journals. The study utilizes a unique data set of individual-specific information for 714 academic economists. The multivariate regression analysis shows that both teaching and service commitments reduce scholarly work in peer reviewed journals. The paper also presents an analysis of the data disaggregated by gender. While the impact of teaching and service on productivity appears roughly similar, the results indicate that collaborative efforts, whether formal or informal, benefit women's publication efforts more than their male counterparts
\end{abstract}

\section{INTRODUCTION}

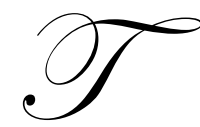

than are men.

he increasing pressure for academics to publish in order to gain tenure and promotion has been accompanied by a renewed interest in gender differences in the process. Ginther and Kahn (2004) and McDowell, Singell and Ziliak (2001) find that women are less likely to receive tenure and promotion

Numerous researchers address the primary underlying contributor to this inequality, differences in publications in peer reviewed journals. While Davis and Patterson (2000) and Bodenhorn (1997) find no gender effects in publication rates, numerous other studies of research productivity find that women are less likely to publish than men (Broder, 1993; Fish and Gibbons, 1989; Barbezat, 1992; McDowell and Smith, 1992; Maske, Durden and Gaynor, 2003). Of these studies of academic productivity, only Maske, Durden and Gaynor (2003) use individualspecific data, that collected from a 1989 survey. The current study examines gender differences in publication rates using an individual-specific data base comprised of 704 economists collected in 2003. Responding to an online survey, these economists provided extensive information regarding their teaching and service commitments as well as personal and institutional information. Using this data, the publication record of each respondent was then obtained from EconLit. Together these data constitute a rich field for the systematic study of gender differences in research productivity.

Section II of the paper presents a model of research productivity and the data used in our analysis. Section III provides the empirical evidence and Section IV presents our summary and conclusions.

\section{THE MODEL AND THE DATA}

Fender, Taylor and Burke (2005), model academic scholarship as a utility maximization problem. Scholars maximize the production of articles subject to the constraint of time. Thus, productivity (P) may be expressed as a 
function of the alternative use of the academic's time (teaching and service), institutional support for research, and other individual-specific factors. ${ }^{1}$ Productivity can thus be modeled as:

$\mathrm{P}=\mathrm{f}($ Teaching, Service, Institutional, Personal)

Where Teaching, Service, Institutional and Personal are each vectors that contain variables related to teaching load, service commitments, departmental/institutional characteristics, and personal demographics, specifically. The measure of productivity and the regressors are described below.

To estimate the theoretical model, data was gathered from a web-based survey conducted in Spring 2003. The survey produced 714 usable responses from academic economists in the U.S. ${ }^{2}$ The survey asked for a variety of information related to economists' human capital and workplace characteristics. Many of the time-varying characteristics were limited to the 5 year period from 1998 through 2002 . While this time period is somewhat arbitrary, it is a sufficient period to reflect conditions over time without being so long as to make recall difficult and thus reduce the survey response rate.

\section{Scholarly Productivity}

The primary outlet for advancing economic scholarship is publication in peer reviewed journals; thus the number of peer reviewed articles (as found in EconLit) over the period 1998-2002 is used to create a measure of each respondent's research productivity. This measure is consistent with that used by Maske, Durden and Gaynor (2003) and McDowell and Smith (1992). In total, the individuals in this sample published 2010 articles in 378 different journals. Table 1 provides the mean for both the dependent and independent variables for the overall sample (column 1), for women (column 2) and for men (column 3). Column 4 indicates whether the means for are significantly different for men and women. Consistent with much of the previous research, the mean number of publications for women, 1.81, is statistically lower than the mean for men, 2.58. The histogram of publications by gender presented in Figure 1 emphasizes this disparity. At the lower end of the publication scale, women outnumber men. No women in the sample, however, have more than 10 publications.

\section{Personal Characteristics}

Human capital and other individual specific variables affecting the productivity index were obtained from the web-based survey. Human capital variables of interest in this study include experience and education measures. Other personal factors include race, involvement in both scholarly and professional activities, and partnerships with other academic scholars. Each of these variables, discussed below, is believed to have a significant influence on research productivity.

Gains in human capital related to time on the job are expected to generate higher levels of productivity (Maske, Durden, and Gaynor, 2003; Bodenhorn, 1997). Experience and experience squared (defined as the number of years since completion of the Ph.D.) are included to measure the diminishing returns to time on the job.

Like experience on the job, working with other scholars should increase the odds of creating publishable research. The literature on co-authorship indicates productivity gains from joint endeavors, largely based on a division of labor argument. Accordingly, McDowell and Melvin (1983), Barnett, Ault, and Kaseman (1988), Davis and Patterson (2000), and Maske, Durden and Gaynor (2003) Fender, Taylor and Burke (2005) and Taylor, Fender and Burke (forthcoming) all find positive returns to co-authorship. The co-authorship variable included in the model is measured as the average number of coauthors per published article and enters the equation both directly and squared to reflect diminishing returns to coauthorship.

\footnotetext{
${ }^{1}$ For additional information on modeling scholarly productivity, see Maske, Durden and Gaynor (2003) and McDowell and Melvin (1983). ${ }^{2}$ E-mail addresses were obtained from Hasselback (2002). 4,864 economists were asked to complete the survey. There were 907 responses yielding a participation rate of roughly $19 \%$.
} 
Figure 1. Distribution of Publications by Gender

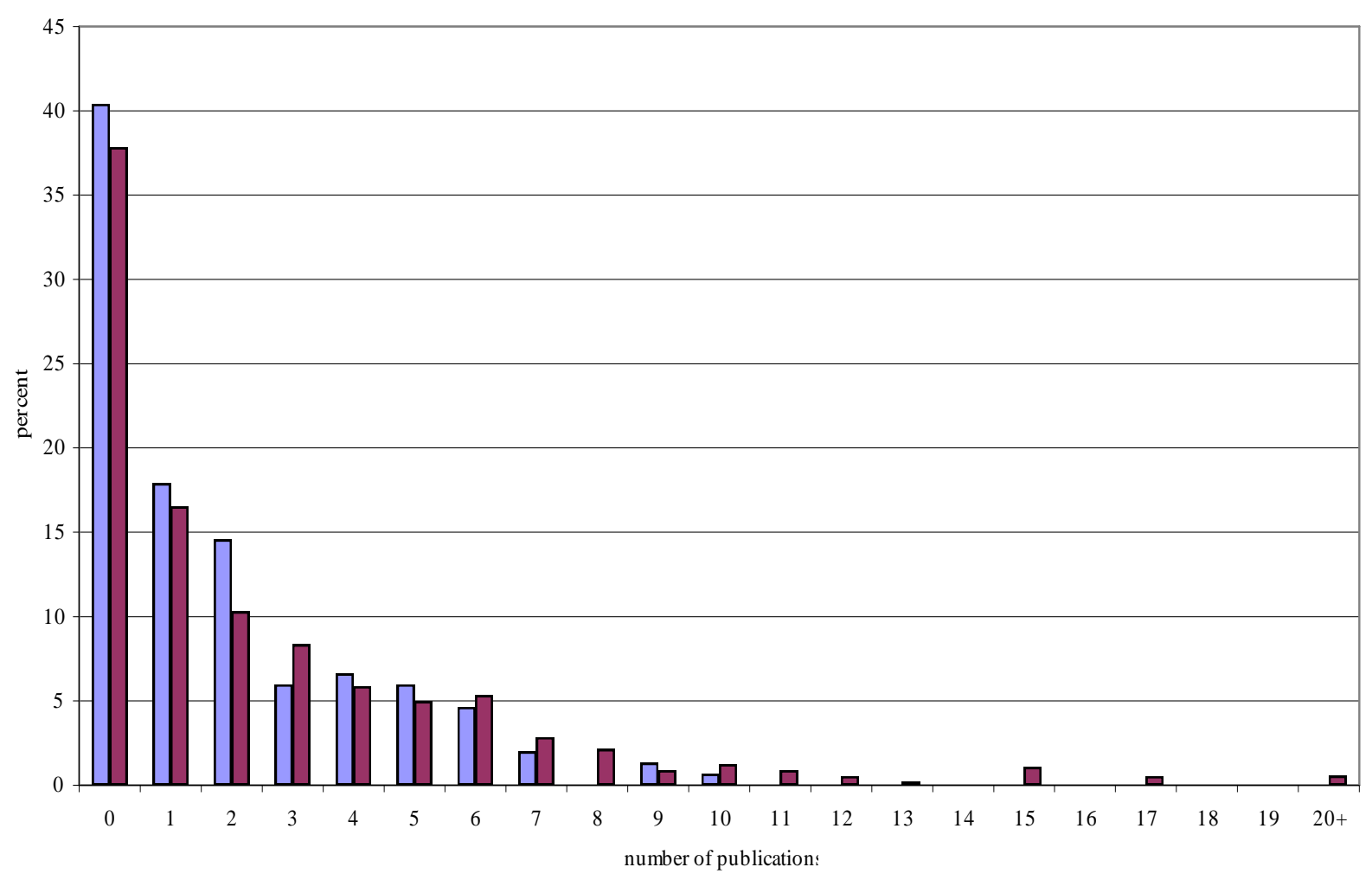

口Females $\square$ Males

The number of years required to complete the Ph.D. (Years to Ph.D.) and the number of manuscripts under review (Review) before acceptance of the first job may also be predictors of future productivity. Submissions early in one's career should be a positive predictor of future publication success, while years to Ph.D is expected to be inversely related.

This study also recognizes the potential effects of certain professional activities on productivity. Many economists choose to present their work at professional conferences. These presentations are assumed to positively impact publication as they provide a valuable mechanism for pre-submission feedback and impose deadlines for completion of manuscripts. Publication of books and chapters may also influence the number of peer reviewed publications, though the sign is ambiguous a priori. These activities, represented by the number of chapters or books over the time period, may either complement or detract from the generation of articles.

Race is included as a regressor in the analysis with a value of 1 if the respondent is Caucasian and 0 otherwise. The impact of race is uncertain a priori.

The second and third columns of Table 1 presents the mean values of these personal characteristics disaggregated by gender. The men in the group have statistically more experience, more peers who publish, and more books and chapters in books than do the women. Women require statistically more time to complete the Ph.D. than do men. 


\section{Institutional Variables}

Institutional attributes, such as degrees offered, departmental environment, and type of institutional support are characteristics of the department or institution in which the respondent works that may influence productivity. To reflect the highest degree in economics offered by the respondent's department, binary dummies for Masters Degree and Doctoral Degree are included in the model. With the resources available to and the research expectations of faculty at doctoral granting departments, one would expect faculty in doctoral granting departments to publish more in elite journals than faculty at undergraduate departments. Similar logic applies to faculty at master's granting institutions.

Beyond the type of degree offered by the department, the research climate of the department is expected to influence quality publication as well. This effect is proxied by two variables. The first variable, summer stipends to support research activities, is measured as the number of stipends received over the five year period under review. Such grants reduce the need to teach in the summer for supplemental income and are an indication of departmental research support. A second indication of a department's research environment is the number of peers who publish. The presence of scholarly active peers is expected to increase productivity as it enhances both formal and informal collaboration and may produce a competitive environment of "keeping up" with one's colleagues. This variable is entered as the self-reported percentage of full-time, tenure-track economics faculty at the individual's institution who have published in peer reviewed journals in the last five years. As the second panel of Table 1 indicates, this is the only "institutional" variable for which there is a statistical difference by gender with men having more peers who publish in peer-reviewed journals than women.

A final descriptor of the institution used as a regressor is whether the institution is publicly or privately funded. The sign of Support, which takes a 1 if privately funded and 0 otherwise, is uncertain a priori, though Maske, Durden, and Gaynor (2003) find a similar variable negative.

\section{Teaching and Service}

Like both personal and institutional characteristics, professional responsibilities that compete for an academic's time should also influence productivity. In particular, those responsibilities that are scheduled periods of time over which the researcher has little control may dilute the blocks of time available and needed to conduct research. As a result, quality research production is expected to be negatively related to a scholar's two largest time competitors, teaching and service.

The individual's teaching commitment is measured by two variables: (1) teaching load which is the number of credit hours taught in the academic year and (2) summer hours, the number of credit hours taught in the summer session(s). Service commitment is measured by three increasingly time consuming activities: Committee is the average number of committees on which a person serves in a typical year, exclusive of the average number of committees an individual chairs; Committee Chair is the average number of committees a person chairs in a typical year; and Department Chair is the number of years an individual has served as department chair or program director in the last five years.

The data in the third panel of Table 1 indicate that women teach statistically more credit hours during the academic term though there are no differences in summer hours taught. While women serve on more committees than do men, men have statistically greater obligations as committee or departmental chairs.

\section{EMPIRICAL ESTIMATION AND RESULTS} for men:

We estimate the following model by ordinary least squares for (1) the aggregate data, (2) for women and (3) 
$\mathrm{P}=\square_{0}+\square_{1}$ Gender $+\square_{2}$ Experience $+\square_{3}$ Expsq $+\square_{4}$ Coauthor $+\square_{5}$ Coauthorsq $+\square_{6}$ Years to Ph.D. $+\square_{7}$ Review +

$\square_{8}$ Presentations $+\square$ Books $+\square_{10}$ Chapters $+\square_{11}$ Race $+\square_{12}$ Masters $+\square_{13}$ Doctoral $+\square_{14}$ SumStipend $+\square_{15}$ Peers

$+\square_{16}$ Support $+\square_{17}$ TeachingLoad $+\square_{18}$ SummerHours $+\square_{19}$ Committee $+\square_{20}$ ComChair $+\square_{21}$ DeptChair

\section{Personal Characteristics}

Estimated coefficients for the aggregate sample are presented in Column 1 of Table 2 with absolute tstatistics in parentheses below the coefficients. The first panel of Column provides information for the personal characteristics of respondents. Consistent with previous findings of Taylor, Fender, and Burke (forthcoming), Fender, Taylor and Burke (2005), Maske, Durden , and Gaynor (2003), Broder (1993), Fish and Gibbons (1989), Barbezat (1992) and McDowell and Smith (1992), men publish significantly more than women. Experience also plays the expected role with significantly positive but diminishing returns to time on the job. Similar results are found for coauthorship. Consistent with Taylor, Fender and Burke (forthcoming) and Fender, Taylor and Burke (2005), working with coauthors pays off in term of significantly higher productivity, though again with diminishing impact. As found by Maske, Durden, and Gaynor (2003), race has no statistically significant impact on productivity.

The other personal characteristics are measures of how aggressively one pursue's the scholarly career and all are significant with the exception of books published. The length of time required to complete the Ph.D. negatively impacts productivity while the number of articles under review before accepting the first job significantly increases productivity. Finally, presentations at professional meetings and chapters published increase scholarly publication in peer reviewed journals.

\section{Institutional Characteristics}

The environment in which one works influences the individual's scholarly productivity. As compared to peers at institutions which offer only the undergraduate degree in economics, colleagues at doctoral granting departments publish significantly more. There is no significant difference between individuals at master's granting departments and undergraduate departments. Departmental support in the form of summer stipends frees the individual to work on research projects and significantly increases scholarly productivity. Surprisingly, the existence of peers in the department who publish is not significant. Contrary to the findings of Maske, Durden, and Gaynor (2003), individuals at privately-funded institutions publish less than those at publicly funded institutions.

\section{Teaching and Service Commitments}

As expected, the two primary competitors for the academic's time, teaching and service, have a significantly negative impact on productivity. Teaching, whether in the academic year or during the summer, reduces publication in scholarly journals. While service on committees doesn't impact productivity, the more time-intensive responsibilities of service as committee chair or departmental chair result in significantly fewer publications. The elasticities for department chair (-0.45) and teaching load (-0.22) highlight the opportunity costs of these activities in terms of reduced productivity.

\section{Gender Effects}

The gender coefficient in the aggregate sample is statistically significant supporting the findings of others that as a whole, men publish more than women. Columns 3 and 5 of Table 2 provide a closer examination of the factors driving publication rates for the two groups. The aggregate estimation constrains the coefficients to be equal for both genders. Separate estimations allow the effects of regressors to vary across the genders.

In terms of personal characteristics, sign and significance of coefficients are consistently similar across gender specifications with the exception of chapters in books which is statistically positive for men but insignificant for women. Race is not significant in either equation. The institutional coefficients of note are peers who publish which has a significant impact only for women and type of institutional support which is significant only for men. Teaching load significantly impacts both genders, though teaching summer hours only influences publication by men. 
None of the committee factors are significant for women, though service as both committee and departmental chairs reduces peer-reviewed scholarship for men.

The elasticities accompanying the coefficient estimates (given in Columns 4 and 6) tell an interesting story, particularly in terms of the influence of co-authors and peers on publication levels. While the coefficient of coauthors is significant for both groups, a one percent increase in the number of co-authors has a much larger effect on women (0.61) than on men (0.39). Not only are co-authors important for women, but the presence of peers who are scholarly active is significantly important for women also, though not for men. This is mirrored in the elasticity values which show that an equal one percent increase in scholarly active peers has no impact on men but increases women's productivity by 0.37 percent.

\section{CONCLUSION}

The purpose of this study is to examine the impact of personal characteristics, institutional factors, and timecompeting workplace requirements on scholarly productivity in peer-reviewed economics journals. The study utilizes a unique data set of individual-specific information for 714 academic economists. The multivariate regression analysis shows that both teaching and service commitments reduce scholarly work in peer reviewed journals. The paper also presents an analysis of the data disaggregated by gender. While the impact of teaching and service on productivity appears roughly similar, the results indicate that collaborative efforts, whether formal or informal, benefit women's publication efforts more than their male counterparts.

\section{REFERENCES}

1. Barbezat, Debra A., "The Market for New Ph.D Economists," Journal of Economic Education, 23 (Summer 1992): 262-76.

2. Barnett, Andy H., Richard W. Ault, and David L. Kaserman, "The Rising Incidence of CoAuthorship in Economics: Further Evidence," Review of Economics and Statistics 70 (August 1988): 539-43.

3. Bodenhorn, Howard, "Teachers, and Scholars Too: Economic Scholarship at Elite Liberal Arts Colleges," Journal of Economic Education (Fall 1997): 323-536.

4. Broder, Ivy E., "Professional Achievements and Gender Differences among American Economists," Economic Inquiry 31 (January 1993): 116-27.

5. Davis, Joe C. and Debra Moore Patterson. "Determinants of Variations in Journal Publication Rates of Economists," The American Economist 45:1 (Spring 2000): 86-91.

6. Fish, Mary and Jean D. Gibbons, "A Comparison of the Publications of Female and Male Economists," Journal of Economic Education, 20 (Winter 1998): 93-105.

7. Fender, Blakely F., Susan W. Taylor, and Kimberly G. Burke, "Making the Big Leagues: Factors Contributing to Publication in Elite Economics Journals," Atlantic Economic Journal, 33:1 (March 2005).

8. Ginther, Donna K., and Shulamit Kahn, "Women in Economics: Moving Up or Falling Off the Academic Career Ladder?” Journal of Economic Perspectives, 18:3 Summer 2004, pp. 193-214.

9. $\quad$ Hasselback, James R., 2002 Prentice Hall Guide to Economics Faculty. Prentice Hall, 2002.

10. Maske, Kellie L., Gary C. Durden and Patricia Gaynor, "Determinants of Scholarly Productivity Among Male and Female Economists," Economic Inquiry 41 (October 2003): 555-564.

11. McDowell, John M., Larry D. Singell Jr. and James P. Ziliak, "Gender and Promotion in the Economics Profession." Industrial and Labor Relations Review. (2001) 54:2, pp. 224 - 44.

12. McDowell, John M. and Michael Melvin, "The Determinants of Co-Authorship: an Analysis of the Economic Literature," Review of Economics and Statistics 65 (February 1983): 155 - 160.

13. McDowell, John M. and Janet Kiholm Smith, "The Effect of Gender Sorting on Propensity to Coauthor: Implications for Academic Promotion," Economic Inquiry 30 (January 1992): 68-82.

14. Taylor, Susan W., Blakely F. Fender, and Kimberly G. Burke. "Unraveling the Academic Productivity of Economists: The Opportunity Costs of Teaching and Service," Southern Economic Journal (forthcoming). 